\title{
DÜBLIN
}

Technological University Dublin

ARROW@TU Dublin

\section{Detection of trends in the 7-day sustained low-flow time series of Irish rivers}

\author{
Ahmed Nasr \\ Technological University Dublin, ahmed.nasr@tudublin.ie \\ Michael Bruen \\ University College Dublin
}

Follow this and additional works at: https://arrow.tudublin.ie/engschcivart

Part of the Civil and Environmental Engineering Commons

\section{Recommended Citation}

Ahmed Nasr \& Michael Bruen (2017) Detection of trends in the 7-day sustained low-flow time series of Irish rivers, Hydrological Sciences Journal, 62:6, 947-959, DOI: 10.1080/02626667.2016.1266361

This Article is brought to you for free and open access by the School of Civil and Structural Engineering at ARROW@TU Dublin. It has been accepted for inclusion in Articles by an authorized administrator of ARROW@TU Dublin. For more information, please contact arrow.admin@tudublin.ie, aisling.coyne@tudublin.ie, gerard.connolly@tudublin.ie.

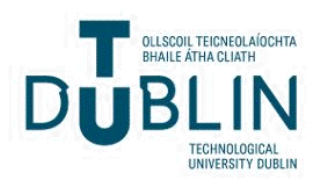


Hydrological Sciences Journal

\section{Detection of trends in the 7-day sustained low-flow time series of Irish rivers}

\section{Ahmed Nasr \& Michael Bruen}

To cite this article: Ahmed Nasr \& Michael Bruen (2017) Detection of trends in the 7-day sustained low-flow time series of Irish rivers, Hydrological Sciences Journal, 62:6, 947-959, DOI: 10.1080/02626667.2016.1266361

To link to this article: https://doi.org/10.1080/02626667.2016.1266361

\section{Published online: 20 Jan 2017.}

Submit your article to this journal ๔

Џll Article views: 264

Q View related articles $\asymp$

View Crossmark data ¿

Citing articles: 2 View citing articles ๘ 


\title{
Detection of trends in the 7-day sustained low-flow time series of Irish rivers
}

\author{
Ahmed Nasr (10) and Michael Bruen ${ }^{\mathrm{b}}$

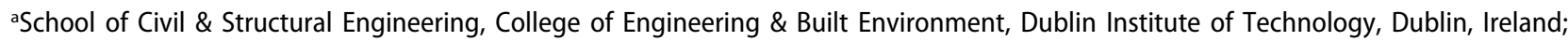 \\ ${ }^{b}$ Dooge Centre for Water Resources Research, University College Dublin, Dublin, Ireland
}

ABSTRACT

A combination of statistical hypothesis testing methods (Mann-Whitney, Mann-Kendall and Spearman's rho) and visual exploratory analysis were used to investigate trends in Irish 7-day sustained low-flow (7SLF) series possibly driven by changes in summer rainfall patterns. River flow data from 33 gauging stations covering most major Irish rivers were analysed, after excluding catchments where low flows are influenced by significant human interventions. A statistically significant increasing trend in the 7SLF series was identified by all three tests at eight gauging stations; in contrast, a statistically significant decreasing trend was identified by all three tests at four stations. The stations with increasing trends are mainly located within the western half of the country, while there is no particular spatial clustering of the stations showing a decreasing trend. Further analysis suggests that the increasing trend in the 7SLF time series persists regardless of the starting year of analysis. However, the decreasing trend occurs only when years prior to 1970 are included in the analysis, and disappears, or is reversed, if only the data from 1970 and onwards are considered. There is strong evidence that the direction of the trends in the 7SLF series is determined mainly by trends in total summer rainfall amounts, i.e. is linked to weather.

\section{ARTICLE HISTORY}

Received 13 July 2015

Accepted 2 September 2016

EDITOR

Z.W. Kundzewicz

ASSOCIATE EDITOR

not assigned

\section{KEYWORDS}

Climate change; 7-day sustained low-flow; visual exploratory analysis; Mann-Whitney method; Mann-Kendall method; Spearman's rho method

\section{Introduction}

Rivers are important water sources and provide multiple water quantity and quality services, including drinking water, effluent dilution, navigation, ecosystem support (environmental flows) and amenities (Gustard and Demuth 2008). Current predictions of climate change impacts on the hydrological regimes of rivers suggest an increase in the variability of river discharge (both an increase in high flows and a decrease in low flows) for about one-third of the global land surface area (Van Vliet et al. 2013). In Ireland, projections of climate change impacts suggest greater annual rainfall but a future decline in summer precipitation amounts, causing decreases in quantity and deterioration in quality of water in rivers in this critical season (McGrath et al. 2005, Steele-Dunne et al. 2008, Fealy and Murphy 2009). This worrying change in the resource will be further aggravated by an expected increased demand for water linked to a growing population. Therefore, to ensure sustainability in water supply and other services provided by rivers, particularly during low-flow periods, there is an urgent need for informed and prudent planning and management of river water resources. For this, it is important to identify the most vulnerable river reaches, particularly those that already have significant variability in magnitude and timing of low-flow events.

There are a number of indices that can be used to assess the vulnerability of a river's uses to extremes of low flows. These were reviewed by Smakhtin (2001) along with methods for their estimation. In Ireland, the most widely used low-flow indices for water resources management and decisions based on environmental flows are measures of the dry weather flow, such as the flow magnitude that has been exceeded $95 \%$ of the time (Q95), and the annual 7-day sustained low-flow (7SLF) (e.g. MacCárthaigh 1987, 1989, Gustard et al. 1992). The latter is the lowest flow not exceeded in any seven consecutive day period in each year and is included in this study to maintain compatibility with results obtained from previous analysis with this index by Murphy et al. (2013). By focussing exclusively on low flows, this study extends that previous study by including data from an additional 25 gauging stations not used in the previous study.

Substantial flow variability, due to general climate variability and other non-climate-related influences such as land-use changes, renders the detection of climate change signatures in river flow data a challenging process (Kundzewicz 2003). Overcoming this 
challenge requires a good understanding of the variability in climate drivers, particularly rainfall, which may explain the corresponding variability in river flows. This in turn assists in verifying climate-driven trends in river flows detected by robust trend detection methods based on solid statistical theories. In previous studies of precipitation for the area of this study, Murphy and Washington (2001) found a strong relation between the North Atlantic Oscillation (NAO) and rainfall variability in the UK and Ireland. Also Folland et al. (2009), who studied the effect of the summer NAO on northwest European climate, found a relationship between the summer NAO index and summer rainfall and that summer rainfall in England and Wales has increased since the mid-1970s.

Kundzewicz and Robson (2000) noted that changes in the pattern of any hydrological series, including the 7SLF time series, may occur either abruptly (a step change) or gradually (a trend) or may take more complex forms. They also added that changes may be seen in the mean values, in the variability or in the seasonality of the river flow regimes. The success of any quantitative method to detect these trends depends mainly on two factors, identified by Westmacott and Burn (1997) as: (i) the availability of accurate flow records gathered over an extended period; and (ii) the flow data must come from unregulated locations in the rivers selected for analysis. Trend detection methods can be divided into two categories: statistical methods and exploratory graphical techniques, and both are used here.

The most widely used statistical significance tests are trend detection tests (e.g. Kundzewicz and Robson 2000, Yue and Pilon 2003, Rougé et al. 2013) and changepoint detection methods (e.g. Xiong and Guo 2004, Rougé et al. 2013), which were also reviewed by Kundzewicz and Robson (2000). Changes in pattern detected by these statistical tests can then be examined visually using exploratory graphical data analysis techniques, in which the data are plotted and, if appropriate, a trend line can be fitted and its significance estimated.

Among other total-flow and low-flow indicators, the time series of the annual minimum 7-day mean flow (referred to here as the 7-day minima series) at selected benchmark catchments in the UK were analysed by Hannaford and Marsh (2006), seeking climate-driven changes. They applied three different methods of testing for significant trends, namely the Mann-Kendall, Spearman's rank correlation coefficient, and linear regression methods. In the UK, there was no evidence for trends in the magnitude of the 7-day minima in the benchmark network and this is supported by more recent analyses, e.g. Marsh and Dixon (2012).
However, in Ireland, Kiely (1999), using the MannWhitney-Pettitt test, reported climate-driven trends in mean river flows. More recently, Murphy et al. (2013), using the Mann-Kendall and Theil-Sen tests, reported similar trends in a number of river flow quantiles including the 7SLF. The latter study revealed that low-flow indicators are generally dominated by:

(a) increasing trends, some of which are statistically significant; and

(b) extreme low values at the start (most of their series start in the 1970s and the mid-1970s was a drought period) and high values at the end (recent wet summers) of the time series. These particular circumstances may have had a large influence on the detection of trends.

This study seeks to extend the previous work and to identify any changes in pattern in the 7SLF of Irish rivers, particularly any change that can be linked to quantifiable changes in climate variables. To achieve this, 33 time series of annual minimum 7SLFs from different gauging stations, described in Section 2, across all river basins in Ireland were analysed in a systematic way, as discussed in Section 3. The selected gauging stations have minimal human confounding factors and, hence, any detected trend may be related to changes in the climate, either in the form of natural climate variability or as anthropogenic climate change. Results of the trend analysis of the 7SLF time series are discussed in Section 4, which is followed by a presentation of the summary and conclusions in Section 5.

\section{Data used in analysis}

Thirty-three separate annual minimum series of the 7SLF index were prepared from daily mean river flow data for 33 gauging stations in Ireland. These data were provided by the Irish Office of Public Works (OPW) and the Irish Environmental Protection Agency (EPA), each of which has dedicated hydrometric sections responsible for measuring river flows. The 33 gauging stations were carefully selected from a total of over 800 stations using the following three criteria: (a) reliability of low-flow rating curves; (b) length of data record; and (c) least amount of confounding factors such as human activities, channel dredging or large impoundments in their catchments. This produced a set of the most natural catchments with the best opportunity to detect long-term trends in river low-flow series.

The reliability of the low-flow rating curves (criterion (a)) was assessed by reviewing a tagged rating curve quality code given to each point in the flow data series by the hydrometric organization responsible for each 
Table 1. List of stations used in the study.

\begin{tabular}{|c|c|c|c|c|c|c|}
\hline Station no. & Station name & River & Catchment & $\begin{array}{l}\text { Start of record } \\
\text { (dd/mm/yyyy) }\end{array}$ & End of record & $\begin{array}{c}\text { Length of 7SLF } \\
\text { series (years) }\end{array}$ \\
\hline 01041 & Sandy Mills & Deele & Foyle & $01 / 10 / 1973$ & $23 / 04 / 2002$ & 25 \\
\hline 01043 & Ballybofey & Finn & Finn & 01/10/1972 & $01 / 02 / 2009$ & 26 \\
\hline 03051 & Faulkland & Blackwater & Blackwater & 26/03/1975 & $17 / 02 / 2009$ & 28 \\
\hline 07012 & Slane Castle & Boyne & Boyne & 01/07/1940 & $01 / 01 / 2009$ & 68 \\
\hline 09001 & Leixlip & Ryewater & Liffey & $01 / 11 / 1956$ & $01 / 01 / 2009$ & 48 \\
\hline 09022 & Leixlip Power Station & Liffey & Liffey & $01 / 01 / 1950$ & $02 / 01 / 2009$ & 59 \\
\hline 10002 & Rathdrum & Avonmore & Ovoca & 27/03/1953 & $17 / 01 / 2010$ & 31 \\
\hline 16008 & New Bridge & Suir & Suir & $01 / 10 / 1954$ & $31 / 05 / 2005$ & 46 \\
\hline 18002 & Ballyduff & Blackwater & Blackwater & 01/10/1955 & $01 / 01 / 2009$ & 46 \\
\hline 24004 & Bruree & Maigue & Maigue & 01/10/1972 & $02 / 01 / 2003$ & 30 \\
\hline 24082 & Islandmore & Maigue & Maigue & 01/11/1977 & $20 / 02 / 2001$ & 23 \\
\hline 25002 & Barrington's Bridge & Newport & Shannon Lower & $01 / 10 / 1953$ & $31 / 05 / 1997$ & 41 \\
\hline 25016 & Rahan & Clodiagh & Shannon Lower & 01/01/1952 & $24 / 09 / 2005$ & 49 \\
\hline 25044 & Coole & Kilmastulla & Shannon Lower & 04/06/1961 & $01 / 01 / 2008$ & 32 \\
\hline 26019 & Mullagh & Camlin & Shannon Upper & 01/10/1953 & $21 / 01 / 2002$ & 43 \\
\hline 26054 & The cottage & Little Sheelin tributary & Inny & 01/01/1984 & $07 / 08 / 2008$ & 21 \\
\hline 27002 & Ballycorey & Fergus & Fergus & 01/01/1956 & $31 / 12 / 2006$ & 49 \\
\hline 28001 & Ennistimon & Inagh & Inagh & 01/10/1972 & 06/01/2004 & 30 \\
\hline 29001 & Rathgorgin & Raford & Kilcolgan & $02 / 01 / 1960$ & $30 / 12 / 2000$ & 39 \\
\hline 30002 & Ower Bridge & Black & Corrib & 01/09/1974 & $30 / 12 / 2002$ & 27 \\
\hline 30005 & Foxhill & Robe & Corrib & $01 / 11 / 1955$ & $30 / 06 / 2008$ & 47 \\
\hline 30007 & Ballygaddy & Clare & Corrib & $01 / 12 / 1974$ & $24 / 07 / 2005$ & 28 \\
\hline 31002 & Cashla & Cashla & Cashla & 06/04/1979 & $13 / 04 / 2009$ & 28 \\
\hline 33001 & Glenamoy & Glenamoy & Glenamoy & 06/03/1977 & $23 / 06 / 2009$ & 30 \\
\hline 34009 & Curraghbonaun & Owengarve & Moy & $01 / 02 / 1972$ & $31 / 12 / 1999$ & 25 \\
\hline 34014 & Mill Bridge & Clydagh & Moy & $01 / 10 / 1952$ & $31 / 12 / 2001$ & 48 \\
\hline 35002 & Billa Bridge & Owenbeg & Ballysadare & $01 / 02 / 1972$ & $31 / 12 / 2002$ & 28 \\
\hline 35005 & Ballysadare & Ballysadare & Ballysadare & 02/01/1946 & $01 / 01 / 2009$ & 51 \\
\hline 35011 & Dromahair & Bonet & Garvogue & 01/11/1957 & $18 / 01 / 2004$ & 42 \\
\hline 36092 & Cathaleens Fall Power Station & Erne & Erne & 24/11/1951 & $31 / 12 / 2008$ & 57 \\
\hline 37020 & Valley Bridge & Glenaddragh & Glenaddragh & 23/05/1978 & $15 / 07 / 2009$ & 28 \\
\hline 38004 & Creeslough & Lackagh & Lackagh & 20/09/1945 & $17 / 07 / 2009$ & 51 \\
\hline 39006 & Claragh & Leannan & Leannan & 01/01/1977 & $17 / 07 / 2009$ & 31 \\
\hline
\end{tabular}

gauging station. Following this initial screening, further refinement of the list of sites was made using criterion (b) to choose stations with the longest flow record, and criterion (c) to eliminate stations with confounding factors or significant urbanization.

Table 1 gives details of the 33 selected gauging stations and Figure 1 shows the locations of these stations within the Irish river network. The minimum length of 7SLF series used in the analysis is 21 years, while the maximum length is 68 years. Any year with missing flow values in its low-flow period (generally summer) was inspected to check whether the missing value(s) could have had an impact on the 7SLF for that year; if so, that year was removed from the analysis.

Monthly rainfall data, provided by Met Éireann, were used to calculate the total summer rainfall (TSR) time series for the catchments that showed significant trends. The TSR was calculated as the total amount of rainfall from July to October for each year from 1961 to 2000.

\section{Methodology}

The trend analysis of each annual minimum 7SLF series was conducted in two parts. In the first, the screening part, each time series was subjected to three different statistical change-hypothesis tests to identify the stations showing statistically significant trends. In the second part, the magnitude and significance of the trends were evaluated using a visual analysis of the data, and also by testing the statistical significance of a linear regression trend line fitted to the data. These methods are described in detail in the following sections.

\subsection{Statistical tests}

Two groups of statistical hypothesis testing methods were used in this study.

(1) Test for a step change in the mean with time:

- Mann-Whitney test (non-parametric test)

(2) Tests for trend:

- Mann-Kendall (non-parametric test for trend)

- Spearman's rho (non-parametric test for trend)

Due to complex dependencies on nonlinear dynamic processes that feature cumulative effects and thresholds, climate change could cause step-like changes 


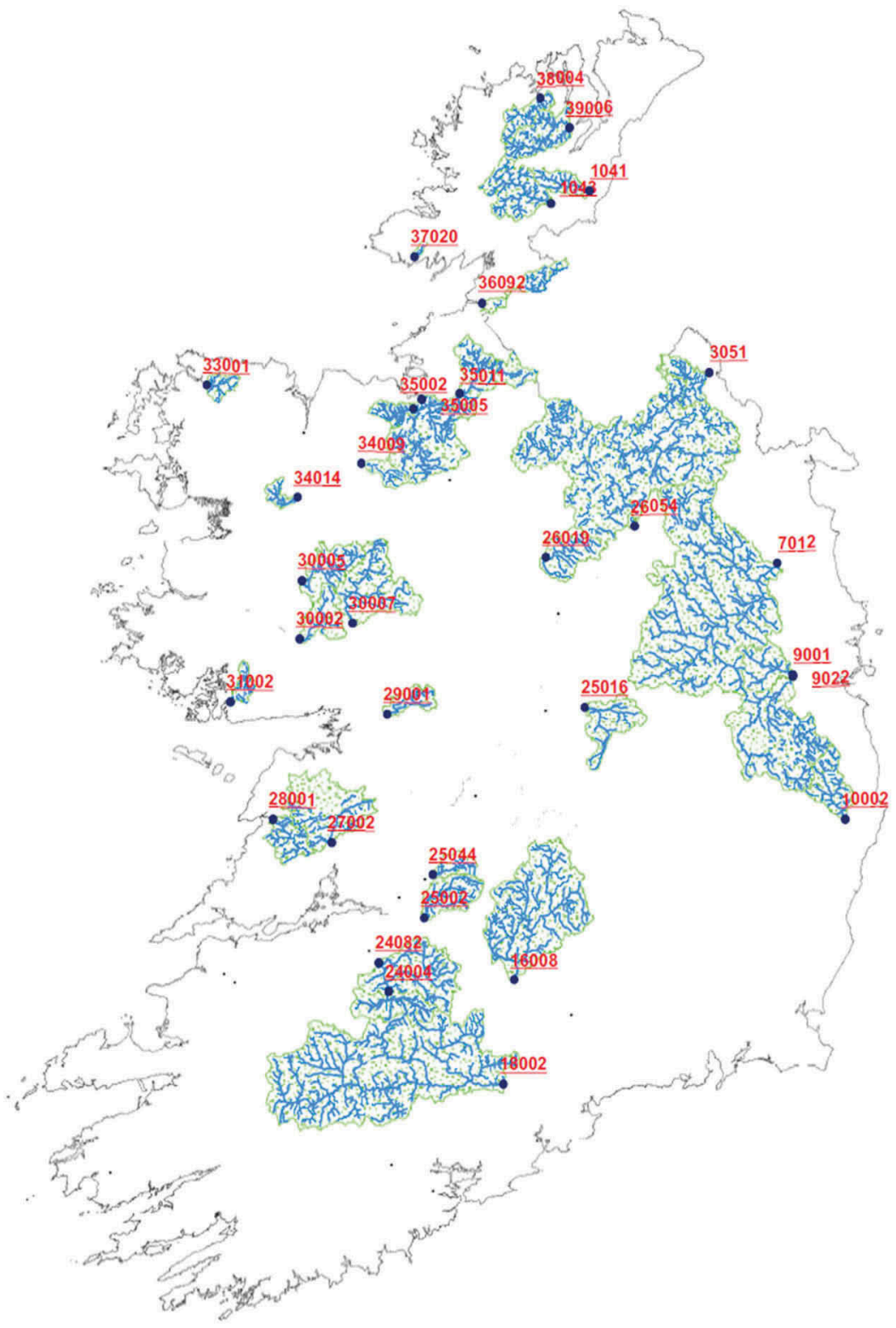

Figure 1. Locations of stations used in the study and their catchments.

(Kundzewicz and Robson 2000). The Mann-Whitney test in Group 1 is an explicit test for the occurrence of such step change. In its basic form, the Mann-Whitney method requires the time of the step change to be specified (Robson et al. 2000), and this is a limitation of this test. The power of the test itself has been assessed by Yue and Wang (2002a), who found it depends on the pre-assigned significance level, magnitude of the change, sample size and the position of its occurrence in the time series. It is also strongly affected by the variation, skewness and distribution type of the time series. The bigger the magnitude of a shift, the more powerful the test is; the larger the sample size, the more powerful the test is; and the bigger the variation within a time series, the less powerful the test is.
Generally, the test has the highest power if a shift occurs at the midpoint of a time series, and this may not be the case in this study. Therefore, the MannWhitney results should be augmented by other tests, and here the Mann-Kendall and Spearman's rho methods are used. These test for trends over the full data period and have been used in other river low-flow studies (e.g. Yue et al. 2002, Hannaford and Marsh 2006, Murphy et al. 2013). In this paper, the results from all three tests are considered together.

One possible complication in the above-mentioned approach could arise if there were serial correlation in the annual 7SLF time series, as this would reduce the power of the trend detection tests (Douglas et al. 2000, Burn and Hag Elnur 2002). If there is a strong climate 
change trend in the time series, this by itself would produce some serial autocorrelation. The influence of such an effect on the hypothesis testing method can be addressed by modifying the method to account for any existing serial correlation in the time series (e.g. Hamed and Rao 1998, Yue and Wang 2002b, Khaliq et al. 2009). Murphy et al. (2013) applied both the original Mann-Kendall method and a modified version based on block bootstrapping to test the significance of trends in the 7SLF series with evidence of autocorrelation at a number of Irish river gauging stations. They showed that differences between the two methods in detecting significant trends occurred in less than $1 \%$ of the stations. Therefore, in this study, only the original hypothesis testing methods have been employed to test for trends in the 7SLF series.

\subsubsection{Mann-Whitney test (rank-sum test)}

This test has a null hypothesis $\left(\mathrm{H}_{0}\right)$ that there is no difference in the mean or the median of two subsamples of the data. For this test, a change point must first be determined in order to split the data series into two sub-samples. Here the Mann-Whitney-Pettitt method, also used by Kiely (1999), was adopted. The test statistic, $U$, is calculated according to Equation (1) and if it is less than a certain critical value, $U_{\mathrm{cr}}$, tabulated by Siegel (1988), which depends on the required confidence level and the sub-sample sizes, $\mathrm{H}_{0}$ can be rejected.

$$
\begin{gathered}
U=\min \left[\left(n_{1} n_{2}+\frac{n_{1}\left(n_{1}+1\right)}{2}-R_{1}\right),\right. \\
\left.\left(n_{1} n_{2}+\frac{n_{2}\left(n_{2}+1\right)}{2}-R_{2}\right)\right]
\end{gathered}
$$

where $n_{1}$ is the size of first sub-sample; $R_{1}$ is the sum of ranks attributed to members of the first sub-sample in the ranked total sample; $n_{2}$ is the size of second subsample; and $R_{2}$ is the sum of ranks attributed to members of the second sub-sample in the ranked total sample.

For large samples, $U$ is approximately normally distributed with mean, $\mathrm{E}(U)$, and variance, $\mathrm{V}(U)$, given by:

$$
\begin{gathered}
E(U)=\frac{n_{1} n_{2}}{2} \\
V(U)=\frac{n_{1} n_{2}\left(n_{1}+n_{2}+1\right)}{12}
\end{gathered}
$$

With this approximation for $U$, the test thus involves calculating a standardized value of the test statistic $Z_{\mathrm{MW}}$ from $U$ as follows:

$$
Z_{\mathrm{MW}}=\frac{(U-\mathrm{E}(U))}{\sqrt{\mathrm{V}(U)}}
$$

This value of $Z_{\mathrm{MW}}$ can be compared with the standard normal distribution critical value for the required significance level. Based on this comparison, the null hypothesis $\mathrm{H}_{0}$ can then be accepted or rejected. Note that if $U$ is taken equal to the first expression in Equation (1) and substituted in Equation (4), the resulting sign of $Z_{\mathrm{MW}}$ will give the direction of the step change (a positive sign for an increasing change and a negative sign for a decreasing change). The $Z_{\mathrm{MW}}$ statistics have been calculated this way in the current study.

\subsubsection{Mann-Kendall test}

The Mann-Kendall test is a non-parametric test (Kendall 1938) which examines a null hypothesis $H_{0}$ that there is no trend in the data. The $n$ time series values of the 7SLF $\left(q_{1}, q_{2}, q_{3}, \ldots, q_{n}\right)$ are replaced by their relative ranks $\left(R_{1}\right.$, $R_{2}, R_{3}, \ldots, R_{n}$ ) (starting at 1 for the lowest up to $n$ ).The test statistic $S$ (Kendall's sum) is given by:

$$
S=\sum_{i=1}^{n-1}\left[\sum_{j=i+1}^{n} \operatorname{sgn}\left(R_{j}-R_{i}\right)\right]
$$

where $\operatorname{sgn}\left(R_{j}-R_{i}\right)=1$ for $R_{j}-R_{i}>0 ; \operatorname{sgn}\left(R_{j}-R_{i}\right)=0$ for $R_{j}-R_{i}=0$; and $\operatorname{sgn}\left(R_{j}-R_{i}\right)=-1$ for $R_{j}-R_{i}<0$.

For $n \geq 8$ and when there are only few tied values in the series, the statistic $S$ is approximated by a normal distribution with mean, $\mathrm{E}(S)$, and variance, $\mathrm{V}(S)$, given by (Mann 1945, Kendall 1975):

$$
\begin{gathered}
E(S)=0 \\
\mathrm{~V}(S)=\frac{n(n-1)(2 n+5)-\sum_{i=1}^{n} t_{i} i(i-1)(2 i+5)}{18}
\end{gathered}
$$

where $t_{\mathrm{i}}$ is the number of ties of extent $i$.

The standardized value of the test statistic $Z_{\mathrm{MK}}$ is computed by:

$$
Z_{\mathrm{MK}}= \begin{cases}\frac{S-1}{\sqrt{\mathrm{V}(S)}} & S>0 \\ 0 & S=0 \\ \frac{S+1}{\sqrt{\mathrm{V}(S)}} & S<0\end{cases}
$$

Values of $Z_{\mathrm{MK}}$ can be compared with the standard normal distribution critical value for the required significance level. Based on this comparison, the null hypothesis $\mathrm{H}_{0}$ can then be accepted or rejected. 


\subsubsection{Spearman's rho test}

Spearman's rho test is a rank-based test that determines whether the correlation between two variables is significant. Here, one variable is taken as an index of time (e.g. the year) and the other as the corresponding annual 7SLF value. Both variables are replaced by their ranks. If the time series consists of $n$ distinct values, the ranks will be the numbers from 1 to $n$, with $n$ corresponding to the highest value in the time series, $n-1$ corresponding to the second highest, and so on. If there are ties (equal values) in the time series, each value in the tie group is assigned the same (mean) rank.

Given a sample dataset $\left\{q_{i}, i=1,2, \ldots, n\right\}$, the null hypothesis $\mathrm{H}_{0}$ of the Spearman's rho test for trend is that all the $q_{i}$ are independent and identically distributed; the alternative hypothesis is that $q_{i}$ increases or decreases with $i$, i.e. that there is a trend. The test statistic $O$ is given by (Sneyers 1990):

$$
O=1-\frac{6 \sum_{\mathrm{i}=1}^{n}\left[\mathrm{R}\left(q_{i}\right)-i\right]^{2}}{n\left(n^{2}-1\right)}
$$

where $\mathrm{R}\left(q_{\mathrm{i}}\right)$ is the rank of the $i$ th observation $q_{i}$ in the sample of size $n$.

For large $n$, the distribution of $O$ is asymptotically normal, with a mean of zero, and a variance of $1 /(n-$ 1), as given by Sneyers (1990).

The standardized value of the test statistic $Z_{\mathrm{SR}}$ is computed by:

$$
Z_{\mathrm{SR}}=\frac{O}{\sqrt{1 /(n-1)}}
$$

The $Z_{\mathrm{SR}}$ can be compared with the standard normal distribution critical value for the required significance level and the null hypothesis $\mathrm{H}_{0}$ can then be accepted or rejected.

\subsection{Exploratory visual analysis of the data}

The exploratory visual analysis is performed here only for those stations for which a significant change has already been indicated by the three significance tests described above. The annual 7SLF series of each of these stations are then plotted against time to show the detected trend visually.

Inferences from the visual analysis can be obtained quantitatively by fitting a line (Equation (11)) to the data and assessing the significance of its slope:

$$
q=a+b t
$$

where $q$ is the 7SLF; $t$ is the time; $a$ is the intercept; and $b$ is the slope of the regression line.
A test statistic $b_{s}$ is calculated as follows:

$$
b_{s}=b / \mathrm{se}
$$

where se is the standard error of the estimate of $b$, which is calculated as:

$$
\text { se }=\sqrt{\frac{1}{(n-2)} \sum_{i=1}^{n}\left(q_{i}-\hat{q}_{i}\right)^{2}} / \sqrt{\sum_{i=1}^{n}\left(t_{i}-\bar{t}\right)^{2}}
$$

where $\hat{q}$ is the value of $q$ estimated using the linear regression model; $\bar{t}$ is the mean of $t$; and $n$ is the number of years analysed.

The null hypothesis is that $b_{s}=0$ (i.e. no trend in the data). However, the critical values of $b_{s}$ for various significance levels are not readily available. Therefore, in this study, an empirical distribution of the $b_{s}$ statistic has been derived by resampling the time series to obtain 10000 realizations of size $n$ using the bootstrap method (Efron 1979). For each realization, a value of $b_{s}$ was calculated and the resulting 10000 values were ordered from the largest to the smallest to determine the critical value (twotailed) for the chosen significance level. For example, the critical values for the $1 \%$ significance level (two-sided test) will correspond to the $0.5 \%$ and the $99.5 \%$ points of the distribution (the ordered sample $b_{s}$ values).

\subsection{Persistence curve for Mann-Kendall $Z_{M K}$ statistic}

The persistence curve for the Mann-Kendall $Z_{\mathrm{MK}}$ statistic is used in this study to assist in identifying the direction of the trend in the 7SLF time series for each station, which shows significant change in all three tests. Murphy et al. (2013) also used the same curves for investigating the persistence of trend in a number of river flow quantiles, including the 7SLF.

To plot the persistence curve for each station, the $Z_{\mathrm{MK}}$ statistic was recalculated a number of times, each time dropping one year from the beginning of the series while keeping the end year fixed. The process was continued until the change year (determined by Mann-WhitneyPettitt method) became the first year of the series.

\section{Results and discussion}

\subsection{Test statistics}

The results from the Mann-Whitney, Mann-Kendall and Spearman's rho tests are presented together in Table 2 for all 33 stations. The significance of the three test statistics is assessed at the $5 \%$ and $1 \%$ levels of significance, shown in Table 2 in bold and italics, respectively. 
Table 2. Results of Mann-Whitney, Mann-Kendall and Spearman's rho tests. Values significant at the $5 \%$ confidence level are shown in bold, while values significant at the $1 \%$ confidence level are shown in italics.

\begin{tabular}{|c|c|c|c|c|c|}
\hline \multirow[t]{2}{*}{ Station } & \multirow[t]{2}{*}{ Direction of trend* } & \multirow[t]{2}{*}{ Year of step change } & \multirow{2}{*}{$\frac{\text { Mann-Whitney } U \text { test }}{Z_{\mathrm{MW}}}$} & \multirow{2}{*}{$\frac{\text { Mann-Kendall test }}{Z_{\mathrm{MK}}}$} & \multirow{2}{*}{$\frac{\text { Spearman's rho test }}{Z_{S R}}$} \\
\hline & & & & & \\
\hline 01041 & I & $1984^{* *}$ & 2.028 & 1.379 & 1.455 \\
\hline 01043 & I & 1997 & 1.999 & 1.102 & 1.106 \\
\hline 03051 & I & 1997 & 3.132 & 3.063 & 3.139 \\
\hline 07012 & I & 1978 & 2.297 & 1.572 & 1.677 \\
\hline 09001 & I & $1984^{* *}$ & 2.795 & 2.711 & 2.272 \\
\hline 09022 & $\mathrm{D}$ & 1988 & -4.131 & -3.432 & -3.742 \\
\hline 10002 & $\mathrm{D}$ & 1967 & -1.747 & -0.306 & -0.412 \\
\hline 16008 & $\mathrm{D}$ & 1994 & -2.770 & -1.117 & -1.205 \\
\hline 18002 & $\mathrm{D}$ & 1994 & -3.152 & -1.667 & -1.791 \\
\hline 24004 & I & $1990 * *$ & 3.006 & 2.748 & 2.871 \\
\hline 24082 & I & $1991^{* *}$ & 0.819 & 0.264 & 0.3986 \\
\hline 25002 & I & $1976^{* *}$ & 1.982 & 1.561 & 1.440 \\
\hline 25016 & $\mathrm{D}$ & 1967 & -0.889 & -0.164 & -0.161 \\
\hline 25044 & I & 1996 & 2.083 & 0.730 & 0.765 \\
\hline 26019 & D & 1971 & -4.770 & -3.537 & -3.719 \\
\hline 26054 & I & 1996 & 1.421 & 0.636 & 0.680 \\
\hline 27002 & $D$ & $1984^{* *}$ & -1.857 & 0.629 & 0.584 \\
\hline 28001 & I & $1984^{* *}$ & 2.836 & 2.534 & 2.581 \\
\hline 29001 & I & 1978 & 3.148 & 2.711 & 2.708 \\
\hline 30002 & I & $1984^{* *}$ & 2.469 & 2.126 & 2.263 \\
\hline 30005 & $\mathrm{D}$ & 1971 & -4.288 & -2.935 & -2.945 \\
\hline 30007 & I & $1984^{* *}$ & 1.870 & 1.443 & 1.346 \\
\hline 31002 & I & $1990^{* *}$ & 1.907 & 1.363 & 1.642 \\
\hline 33001 & $\mathrm{D}$ & 1999 & -1.471 & -0.250 & -0.480 \\
\hline 34009 & I & $1984^{* *}$ & 2.339 & 1.752 & 1.824 \\
\hline 34014 & $D$ & 1971 & -5.704 & -3.085 & -3.896 \\
\hline 35002 & I & $1984^{* *}$ & 2.373 & 2.035 & 2.096 \\
\hline 35005 & I & 1978 & 2.775 & 2.210 & 2.345 \\
\hline 35011 & $D$ & 1966 & -3.909 & -0.455 & -0.909 \\
\hline 36092 & $\mathrm{I}$ & $1991^{* *}$ & 3.175 & 0.819 & 1.176 \\
\hline 37020 & D & 1998 & -2.087 & 1.129 & 0.754 \\
\hline 38004 & I & 1962 & 3.118 & 2.794 & 2.700 \\
\hline 39006 & D & 1987 & -1.116 & -0.374 & -0.307 \\
\hline
\end{tabular}

*I: increasing, D: decreasing.

** Identified as a hydrological drought year in Ireland by MacCárthaigh (1996).

For each station, Table 2 also gives the year of step change, as determined by the Mann-WhitneyPettitt method, and subsequently used to split the time series into two sub-samples for the MannWhitney test. These predicted years of step change were compared to the years of recognized historical extreme hydrological drought. For 13 of the 33 stations, the year of the indicated step change, marked by ${ }^{* *}$ in Table 2, was one of the widely recognized hydrological drought years in Ireland, as identified by MacCárthaigh (1996).

The significance of these step changes in the 7SLF series was confirmed by the Mann-Whitney test for nine of the 13 stations for which the step change occurred in an historical drought year and also for 15 of the other stations (for which the indicated change year did not correspond to an historical hydrological drought year). This brings the total number of stations with significant step changes identified by the MannWhitney test to 24 . Of these 24 stations, only 13 have a significant trend in the 7SLF time series confirmed by both the Mann-Kendall and the Spearman's rho tests. Kundzewicz and Robson (2000) suggested that obtaining statistically significant changes from multiple different tests (e.g. step-change tests, trend tests) provides stronger evidence of change in time series. However, to determine the actual type of change, it is important to examine the test results alongside graphs of the data, and with as much historical knowledge about the data as possible. Therefore, in the current study, unanimous agreement for all three statistics for these 13 consensus stations was used as a strong indicator of the significance of change in the 7SLF series. Hence, these 13 consensus stations are analysed in more detail, as described below.

\subsection{Exploratory visual analysis of the 7SLF time series plots}

Plots of the annual minimum 7SLF series for the 13 consensus stations identified above indicate that 

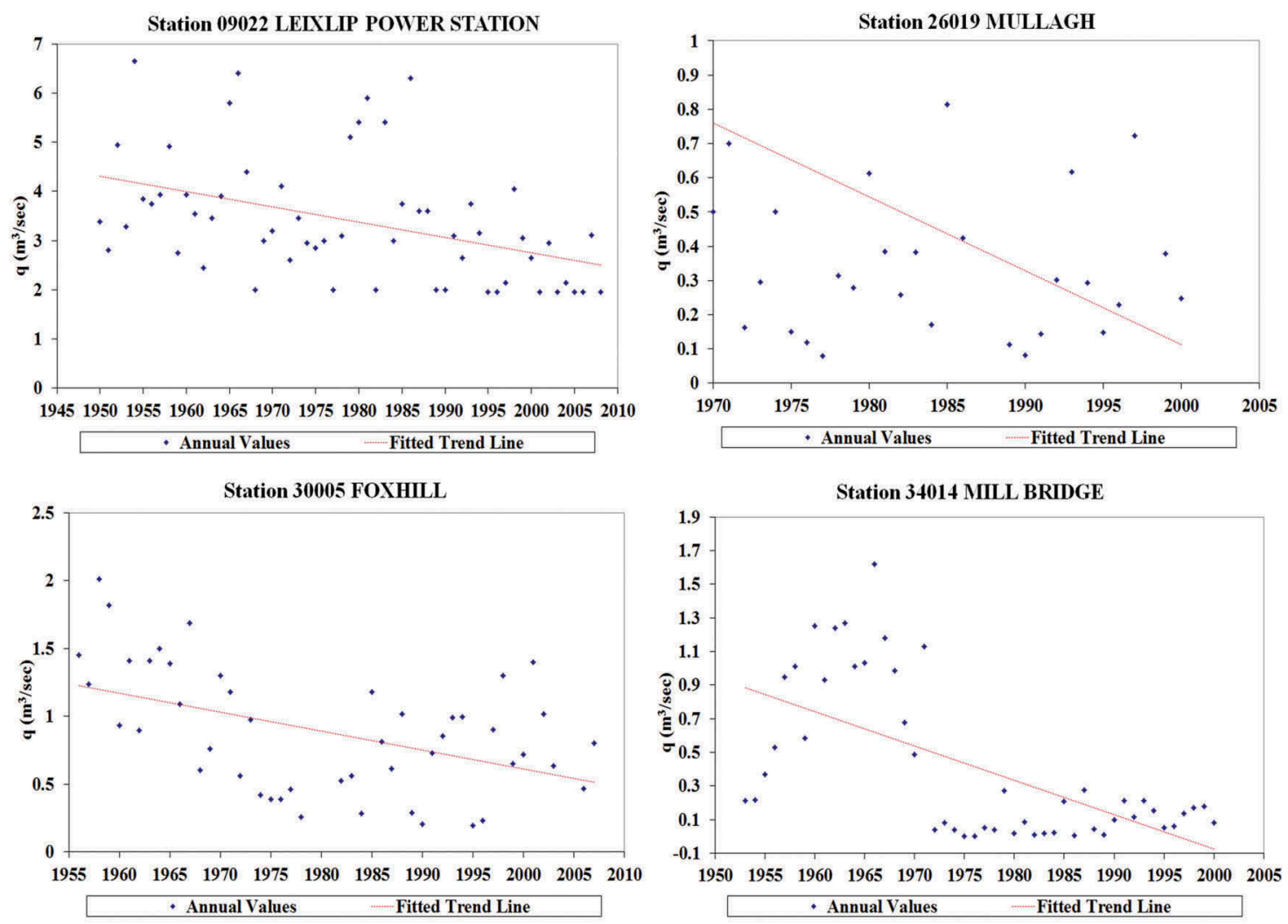

Figure 2. Plots of 7SLF for stations with decreasing flow trends.

four of them have a decreasing trend (Fig. 2), while the remaining nine have an increasing trend (Fig. 3). Table 3 gives the slopes of these trend lines, which were fitted using linear regression. Values of $b_{s}$ from the sample are also given along with their critical values (at the $5 \%$ and $1 \%$ confidence levels) determined from a bootstrap algorithm. The significance level of the results is also shown in Table 3, with bold for the $5 \%$ confidence level and italics for the $1 \%$ confidence level.

The linear regression statistic confirmed the significance of the trend in 12 of the 13 consensus stations. It did not confirm the trend for Station 09001, which was therefore dropped from the subsequent analysis.

\subsection{Spatial distribution of consensus stations}

The locations of the remaining 12 consensus stations with significant change confirmed by all tests are shown in Figure 4. All the stations with an increasing trend, except one, are located within the western half of the country. However, there is no obvious spatial clustering of those stations with a decreasing trend. A similar spatial distribution pattern was found by Murphy et al. (2013), who, using a sub-set of the tests and data used here, suggested significant increases in the 7LSF series at river stations in the south, southwest and northwest of Ireland.

The prevailing wind direction in Ireland is mainly from the west and south or southwest (http://www.met. ie/climate/wind.asp). All of these winds originate over the North Atlantic and thus are influenced by variations in factors such as seawater temperatures and the North Atlantic Oscillation (NAO). Jennings et al. (2000) found that the NAO index is positively correlated with wind speed and rainfall in the west of Ireland.

\subsection{Persistence of trend direction in the 7SLF series}

Willems (2013) showed that in northwestern Europe the 1970s-1980s were drier (fewer rainfall events and lower river flows) than the 1950s-1960s and 1990s-2000s, which had more extreme rainfall and higher river flows. Therefore, any analysis based on records that start in the 1960s could produce trend results completely different from the same analysis conducted on records starting in the 1970s-1980s and the 1940s-1950s. Here, we have investigated this by examining the influence of the starting year of the dataset on the detection of trend. We 

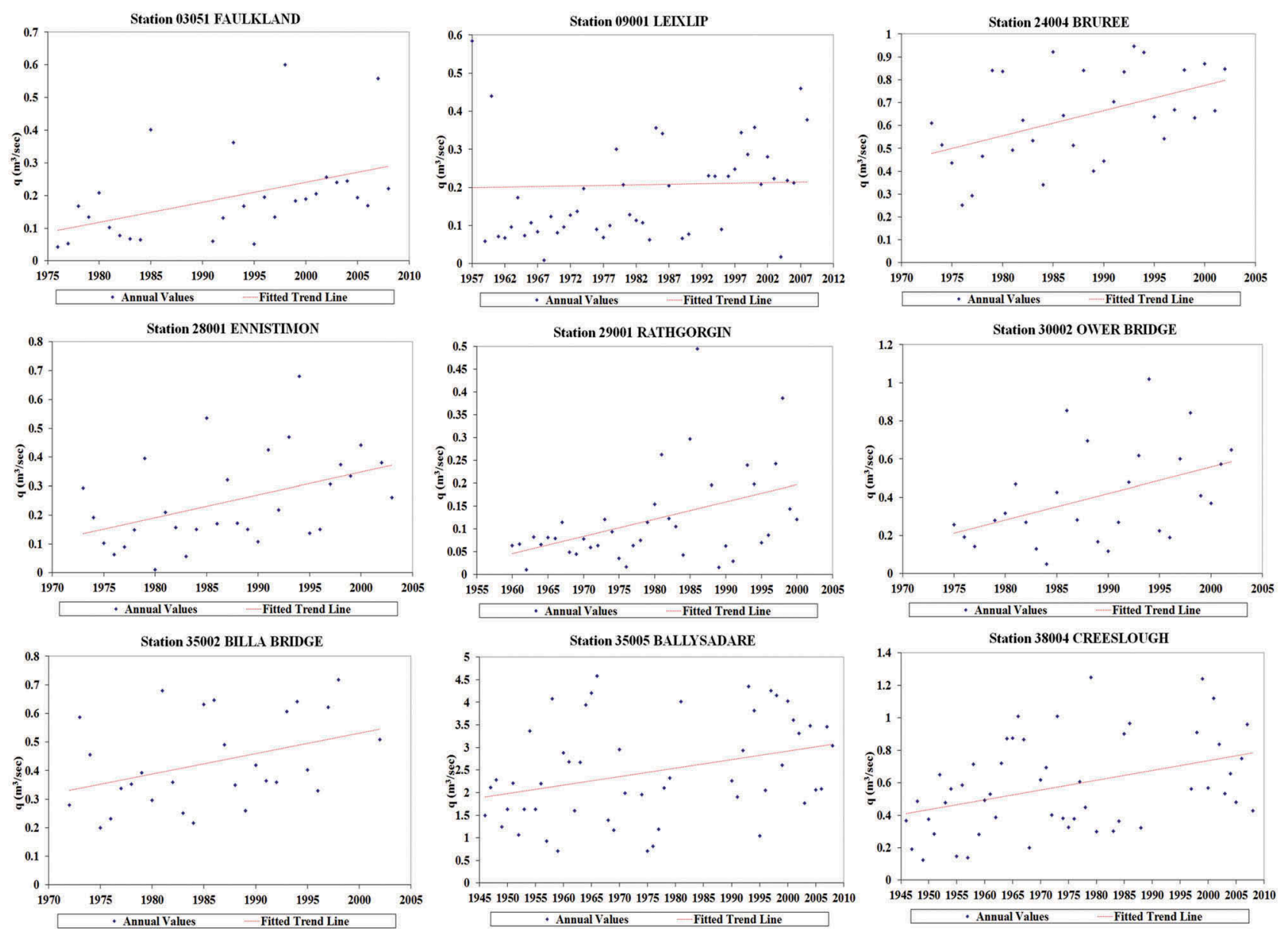

Figure 3. Plots of 7SLF for stations with increasing flow trends.

Table 3. Results of the linear regression test. Values significant at the $5 \%$ confidence level are shown in bold, while values significant at the $1 \%$ confidence level are shown in italics.

\begin{tabular}{lccccc}
\hline Station & Slope of 7SLF trend line $\left(\mathrm{m}^{3} \mathrm{~s}^{-1} \mathrm{year}^{-1}\right)$ & Direction of trend & $b_{s}$ & Absolute critical value at 5\% & Absolute critical value at $1 \%$ \\
\hline 03051 & 0.005476 & $\mathrm{I}$ & 2.675 & 2.132 & 2.775 \\
9001 & 0.003218 & $\mathrm{I}$ & 0.082 & 1.963 & 2.613 \\
9022 & -0.02927 & $\mathrm{D}$ & -3.514 & 1.927 & 2.629 \\
24004 & 0.010938 & $\mathrm{I}$ & 2.932 & 2.035 & 2.695 \\
26019 & -0.01562 & $\mathrm{D}$ & -3.902 & 2.08 & 2.756 \\
28001 & 0.007625 & $\mathrm{I}$ & 2.637 & 2.136 & 2.847 \\
29001 & 0.002667 & $\mathrm{I}$ & 3.033 & 2.059 & 2.594 \\
30002 & 0.013 & $\mathrm{I}$ & 2.464 & 2.08 & 2.752 \\
30005 & -0.01397 & $\mathrm{D}$ & -3.603 & 2.052 & 2.631 \\
34014 & -0.01162 & $\mathrm{D}$ & -5.363 & 2.035 & 2.861 \\
35002 & 0.006689 & $\mathrm{I}$ & 2.124 & 2.031 & 2.653 \\
35005 & 0.018605 & $\mathrm{I}$ & 2.514 & 2.042 & 2.713 \\
38004 & 0.005727 & $\mathrm{I}$ & 3.072 & 2.084 & \\
\hline
\end{tabular}

*: increasing, D: decreasing.

calculated the Mann-Kendall statistic repeatedly for each time series, each time removing a year from the beginning of the series. Figure 5 shows that, as the earlier years of data are removed from the analysis, the statistic tends towards zero, from both the negative and the positive side. This is understandable, as the ability to detect trend should decrease as the duration of the period analysed decreases. However, there is a difference between stations, since those that show an increasing trend for the entire time series continue to show an increasing trend as the time series shortens (the 


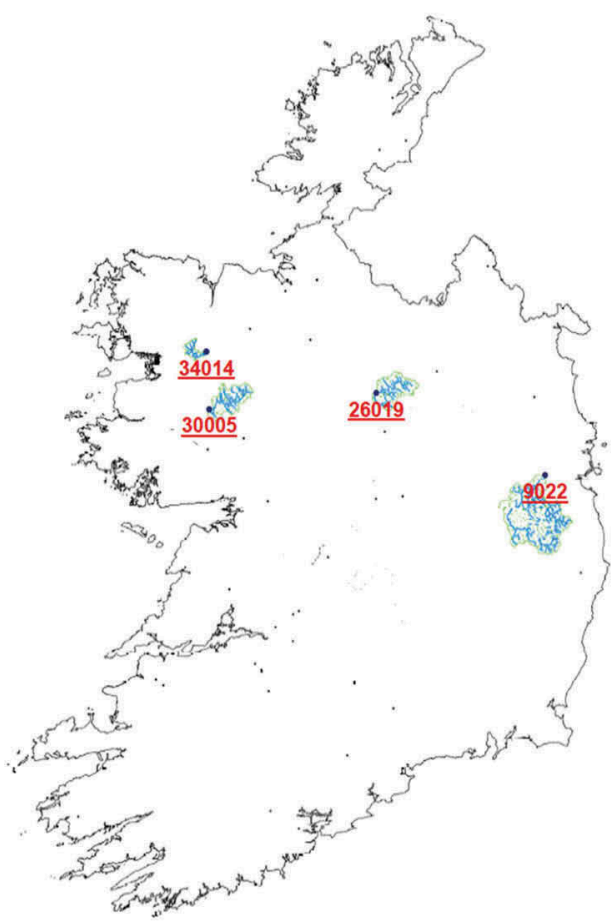

(a)

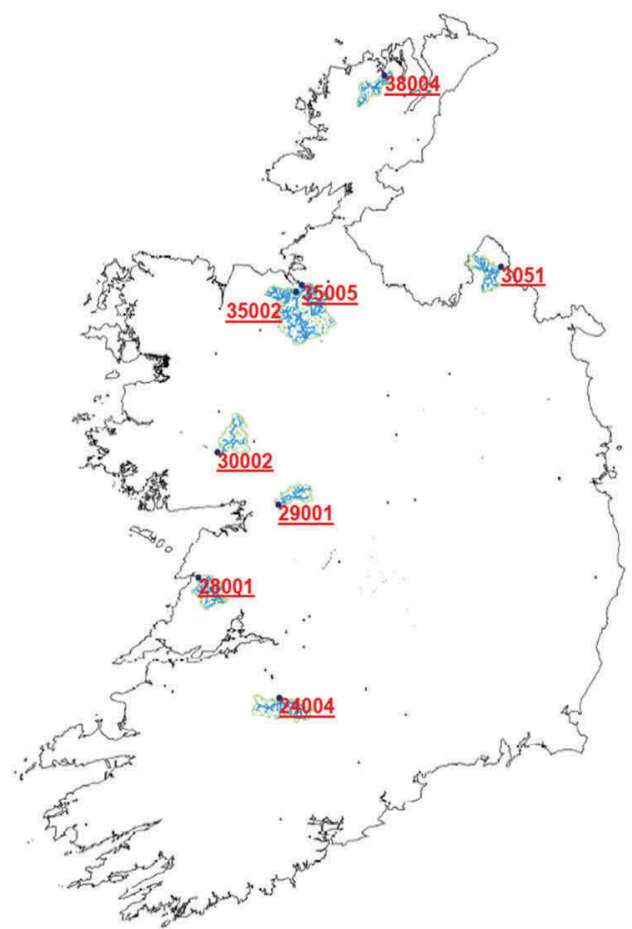

(b)

Figure 4. Locations of stations showing (a) decreasing and (b) increasing trends in all tests.

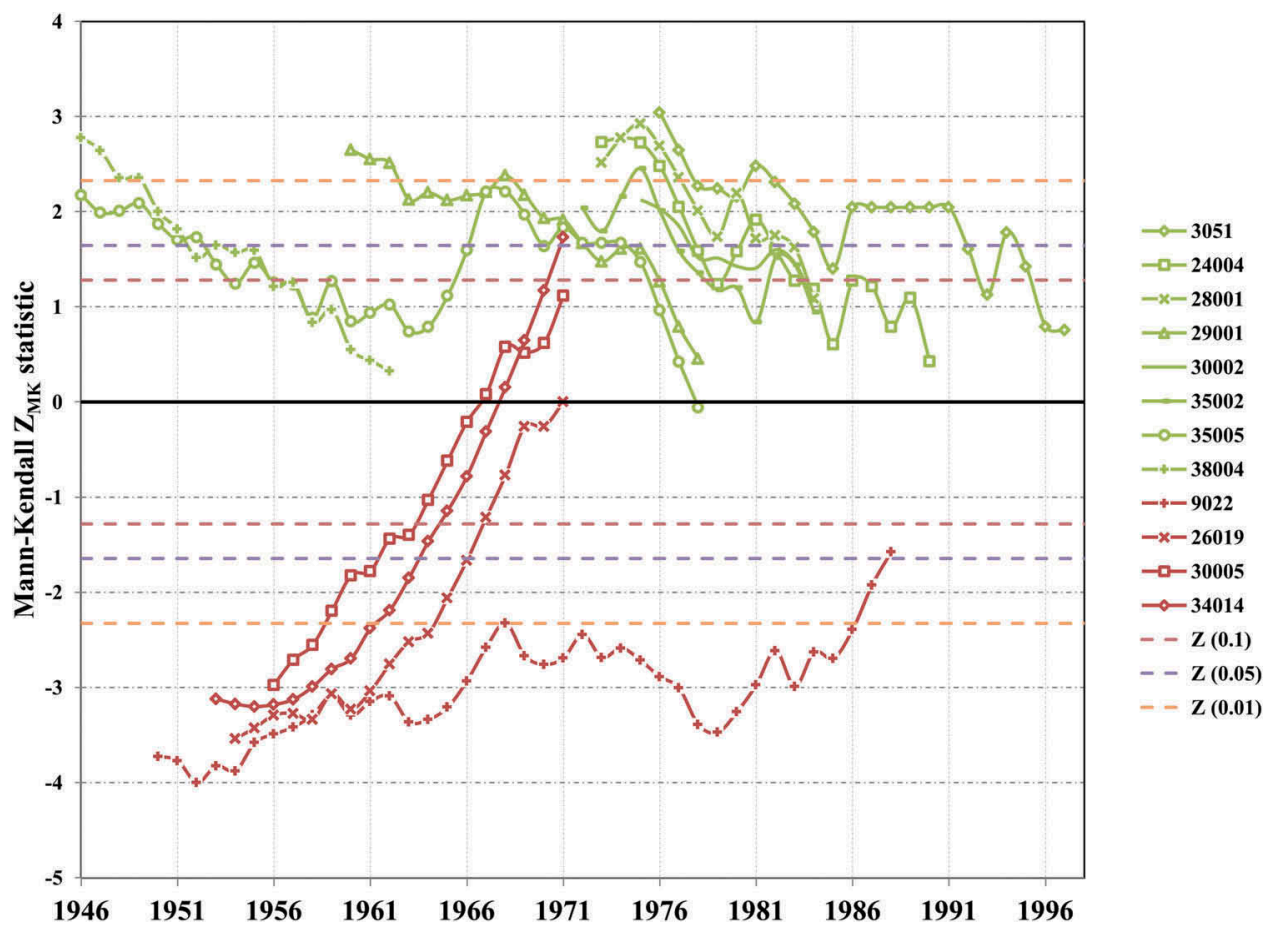

Figure 5. Persistence curve of Mann-Kendall $Z_{M K}$ statistic for stations with decreasing and increasing flow trends.

green lines in Fig. 5). In contrast, most of the stations that initially show a decreasing trend for the full time series (red lines in Fig. 5) change more as the early years are removed and actually cross the zero axis, indicating a change in the direction of the trend. This is consistent with Murphy et al. (2013), who also noticed non-decreasing trends in the 7LSF of Irish rivers when using time series starting at the 1970s. Thus, for the climate setting of our dataset, analyses for stations that show a decreasing trend 
seem to be more sensitive to the starting year of the analysis, while analyses for stations that show an increasing trend seem less sensitive to the starting year and thus are more robust. This, together with the stronger spatial pattern for stations showing an increasing trend, supports the conclusion of increasing low-flow trends in the west of Ireland.

Note that Figure 5 also shows that Station 34014 changes from an initial negative trend to a positive trend significant at the $5 \%$ level after 1968 . To investigate the reason for this, the 7SLF plot in Figure 3 shows that the abrupt decreasing trend in this station occurred mainly due to a significant, unexplained drop in magnitude and variability of the 7SLF values from about 1972.

\subsection{TSR-SLF relationship}

Since there is no evidence of significant land-use or other manmade changes in all stations selected for this study, the inference is that changes in the trend of 7SLF series may be due to changes in rainfall patterns. To investigate this, the link between the trends detected in the 7SLF magnitudes and trends in total summer rainfall (TSR) was examined for each catchment. Only years for which both 7SLF and TSR data were available were used for the analysis. For the 12 consensus stations, the slopes of the trend lines in both TSR and 7SLF are plotted in Figure 6 to check for any correlation between them. It is apparent that the stations with a decreasing trend in 7SLF also have a decreasing trend in
TSR. For the stations with an increasing 7SLF trend, the slopes of the TSR also increase, except for stations 28001, 29001 and 30002, which are shown as triangles in Figure 5. In these three cases, the trend in 7SLF is positive while the trend in TSR is negative. These catchments have a considerable area overlain by well-drained soil, which facilitates infiltration and groundwater recharge. Thus they have some aquifer storage that can retain winter rainfall and can sustain river flows during dry periods despite the decreasing trend in summer rainfall. This physically plausible interpretation may be investigated by applying a suitable hydrological model to simulate subsurface behaviour in these two catchments; however, this is beyond the scope of the current paper.

Thus, we infer that local rainfall patterns during the low-flow periods have a strong influence on the trend of 7SLF values. This has already been suggested in the most recent Met Éireann report on climate averages for Ireland (Walsh 2012) and also by Gleeson et al. (2013). Moreover, it confirms the influence of reduced rainfall on river low flows as previously investigated by MacCárthaigh (1992, 1996), who carried out extensive analysis of rainfall and low-flow data in Ireland for years in the 1970s, a decade that had prolonged periods of dry days and significant low rainfall. The objective of his analysis was to establish the relationship between meteorological drought (defined in terms of rainfall) and hydrological drought (defined in terms of flows) for the entire country. In general, his results

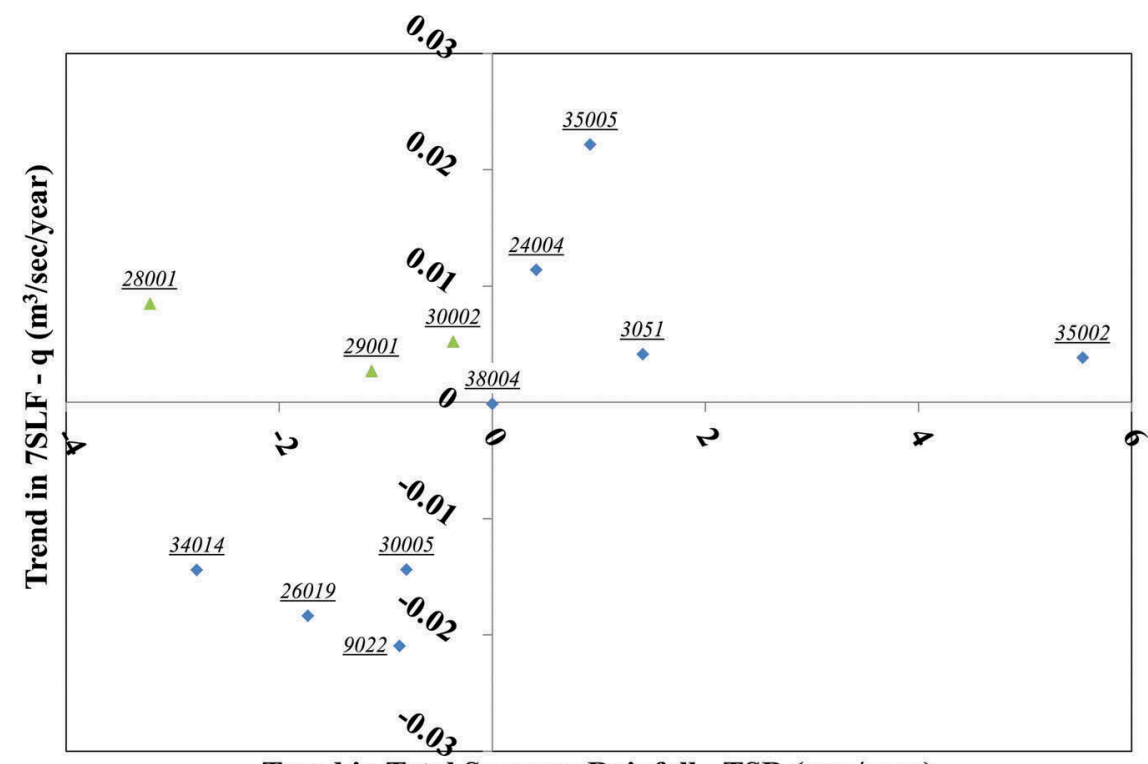

Trend in Total Summer Rainfall - TSR (mm/year)

Figure 6. Slope of TSR trend line against slope of 7SLF trend. 
indicated that a substantial period of meteorological drought during a summer season will result in hydrological drought.

\section{Summary and conclusions}

Trends in low-flow sequences were investigated by analysing the 7-day sustained low-flow (7SLF) time series generated for 33 flow-gauging stations across various river basins in Ireland. Each station was selected on both the basis of record length and quality of low-flow rating, and also for the least amount of anthropogenic influence on flows. Therefore, it is plausible to assume that any detected trend is more likely to be directly related to the influence of climatic variables.

The 7SLF trend detection analysis was accomplished in two steps. In the first step, stations with significant trends in their 7SLF time series were identified using three statistical hypothesis testing methods: the Mann-Whitney non-parametric test; the Mann-Kendall non-parametric test; and the Spearman's rho non-parametric test. Only stations for which all three tests agreed on a trend were retained for the second step. This is a stricter criterion than used in previous studies (e.g. Yue et al. 2002, Hannaford and Marsh 2006, Murphy et al. 2013). In the second step, an exploratory visual analysis of the data was conducted to examine the major trends in the data. Linear regression trend lines were fitted to the data and their significance tested.

After combining the statistical and exploratory visual results a definite increasing trend was confirmed for eight stations and a decreasing trend in four stations. Mapping of the catchments of the 12 stations showed that the stations with an increasing trend are mostly distributed within the western half of the country, while the stations with a decreasing trend are not obviously clustered in any one region. Further investigation showed that the increasing trend in the 7SLF time series is robust and persists regardless of the starting year of analysis. However, the decreasing trends occur only when years prior to 1970 are included in the analysis, and disappear, or are reversed, if only the data from 1970 and onwards are considered. Finally, by including climatic time series represented by total summer rainfall (TSR) in the analysis it was found that trends in the 7SLF series are directly related to trends in the TSR time series.

\section{Acknowledgements}

The authors wish to acknowledge the anonymous reviewers for their detailed and helpful comments to the manuscript.

\section{Disclosure statement}

No potential conflict of interest was reported by the authors.

\section{Funding}

The work of this paper was conducted as part of project no. [2008-FS-WQ-1-S4], funded by the Environmental Protection Agency in Ireland.

\section{ORCID}

Ahmed Nasr (D) http://orcid.org/0000-0003-3240-6016

\section{References}

Burn, D.H. and Hag Elnur, M.A., 2002. Detection of hydrologic trends and variability. Journal of Hydrology, 255 (14), 107-122. doi:10.1016/S0022-1694(01)00514-5

Douglas, E.M., Vogel, R.M., and Kroll, C.N., 2000. Trends in floods and low flows in the United States: impact of spatial correlation. Journal of Hydrology, 240, 90-105. doi:10.1016/S0022-1694(00)00336-X

Efron, B., 1979. Bootstrap methods: another look at the jackknife. The Annals of Statistics, 7 (1), 1-26. doi:10.1214/aos/ 1176344552

Fealy, R. and Murphy, C., 2009. The likely impacts of future climate change on inland waterways and the coastal environment in Ireland. In: B. Kelly and M. Stack, ed. Climate change, heritage and tourism: implications for Ireland's coast and inland waterways. Kilkenny: Heritage Council and Fáilte Ireland, 39-54.

Folland, C.K., et al., 2009. The summer North Atlantic oscillation: past, present, and future. Journal of Climate, 22, 1082-1103. doi:10.1175/2008JCLI2459.1

Gleeson, E., McGrath, R., and Treanor, M., 2013. Ireland's climate: the road ahead. Dublin: Met Éireann.

Gustard, A., Bullock, A., and Dixon, J.M., 1992. Low flow estimation in the United Kingdom. Wallingford, UK: Institute of Hydrology, Report no. 108.

Gustard, A. and Demuth, S., 2008. Estimating, predicting and forecasting low flows. In: A. Gustard and S. Demuth, ed. Manual on low flow estimation and prediction. Geneva, Switzerland: World Meteorological Organization (WMO), Operational Hydrology Report no. 50, 16-21.

Hamed, K.H. and Rao, A., 1998. A modified Mann-Kendall trend test for autocorrelated data. Journal of Hydrology, 204, 182-196. doi:10.1016/S0022-1694(97)00125-X

Hannaford, J. and Marsh, T., 2006. An assessment of trends in UK runoff and low flows using a network of undisturbed catchments. International Journal of Climatology, 26, 1237-1253. doi:10.1002/(ISSN)1097-0088 
Jennings, E., et al., 2000. The North Atlantic Oscillation: implications for freshwater systems in Ireland. Biology and Environment, 100B, 149-158.

Kendall, M.G., 1938. A new measure of rank correlation. Biometrika, 30, 81-93. doi:10.1093/biomet/30.1-2.81

Kendall, M.G., 1975. Rank correlation methods. London, UK: Griffin.

Khaliq, M.N., et al., 2009. Identification of hydrological trends in the presence of serial and cross correlations: A review of selected methods and their application to annual flow regimes of Canadian rivers. Journal of Hydrology, 368, 117-130. doi:10.1016/j.jhydrol.2009.01.035

Kiely, G., 1999. Climate change in Ireland from precipitation and streamflow observations. Advances in Water Resources, 23, 141-151. doi:10.1016/S0309-1708(99)00018-4

Kundzewicz, Z.W., 2003. Water and climate - the IPCC TAR perspective. Nordic Hydrology, 34 (5), 387-398.

Kundzewicz, Z.W. and Robson, A., 2000. Setting the scene. In: Z.W. Kundzewicz and A. Robson, ed. Detecting trend and other changes in hydrological data. Geneva, Switzerland: World Meteorological Organization, WCDMP-45, Report no. 1013, 1-5.

MacCárthaigh, M., 1987. A statistical analysis of river flows - the southern water resource region. Ireland: An Foras Forbartha.

MacCárthaigh, M., 1989. A statistical analysis of river flows the eastern water resource region. Ireland: Water Resources Section, Environmental Research Unit, WR/H17.

MacCárthaigh, M., 1992. Assessment and forecasting of drought flow conditions in Irish rivers. Dublin: Water and Environmental Section, Institution of Engineers of Ireland, $1-33$.

MacCárthaigh, M., 1996. An assessment of the 1995 drought. Wexford, Ireland: Environmental Protection Agency.

Mann, H.B., 1945. Nonparametric tests against trend. Econometrica, 13, 245-259. doi:10.2307/1907187

Marsh, T.J. and Dixon, H., 2012.. The UK water balance: How much has it changed in a warming world? In: Proceedings of the Eleventh National British Hydrological Society Symposium, Dundee, July. Hydrology for a Changing World. British Hydrological Society, 1-5.

McGrath, R., et al., 2005. Climate change: Regional climate model predictions for Ireland. Wexford, Ireland: Environmental Protection Agency.

Murphy, S.J. and Washington, R., 2001. United Kingdom and Ireland precipitation variability and the North Atlantic sea-level pressure field. International Journal of Climatology, 21, 939-959. doi:10.1002/(ISSN)1097-0088

Murphy, C., et al., 2013. HydroDetect: the identification and assessment of climate change indicators for an Irish reference network of river flow stations. Wexford, Ireland: Environmental Protection Agency.

Robson, A., et al., 2000. Statistical methods for testing for change. In: Z.W. Kundzewicz and A. Robson, ed. Detecting trend and other changes in hydrological data. Geneva, Switzerland: World Meteorological Organization, WCDMP-45, Report no. 1013, 46-62.

Rougé, C., Ge, Y., and Cai, X., 2013. Detecting gradual and abrupt changes in hydrological records. Advances in Water Resources, 53, 33-44. doi:10.1016/j.advwatres.2012.09.008

Siegel, S., 1988. Nonparametric statistics: for the behavioural sciences. New York: McGraw-Hill.

Smakhtin, V.U., 2001. Low flow hydrology: a review. Journal of Hydrology, 240, 147-186. doi:10.1016/S0022-1694(00) 00340-1

Sneyers, R., 1990. On the statistical analysis of series of observations. Geneva, Switzerland: World Meteorological Organization, Technical Note no. 143, WMO no. 145.

Steele-Dunne, S., et al., 2008. The impacts of climate change on hydrology in Ireland. Journal of Hydrology, 356, 28-45. doi:10.1016/j.jhydrol.2008.03.025

Van Vliet, M.T.H., et al., 2013. Global river discharge and water temperature under climate change. Global Environmental Change, 23, 450-464. doi:10.1016/j. gloenvcha.2012.11.002

Walsh, S., 2012. A summary of climate averages for Ireland 1981-2010. Dublin: Met Éireann, Climatological Note no.14.

Westmacott, J.R. and Burn, D.H., 1997. Climate change effects on the hydrologic regime within the ChurchillNelson River Basin. Journal of Hydrology, 202, 263-279. doi:10.1016/S0022-1694(97)00073-5

Willems, P., 2013. Adjustment of extreme rainfall statistics accounting for multidecadal climate oscillations. Journal of Hydrology, 490, 126-133. doi:10.1016/j.jhydrol.2013.03.034

Xiong, L. and Guo, S., 2004. Trend test and change-point detection for the annual discharge series of the Yangtze River at the Yichang hydrological station. Hydrological Sciences Journal, 49 (1), 99-112. doi:10.1623/ hysj.49.1.99.53998

Yue, S. and Pilon, P., 2003. Canadian streamflow trend detection: impacts of serial and cross-correlation. Hydrological Sciences Journal, 48 (1), 51-63. doi:10.1623/ hysj.48.1.51.43478

Yue, S., Pilon, P., and Cavadias, G., 2002. Power of the MannKendall and Spearman's rho tests for detecting monotonic trends in hydrological series. Journal of Hydrology, 259, 254271. doi:10.1016/S0022-1694(01)00594-7

Yue, S. and Wang, C.Y., 2002a. Power of the Mann-Whitney test for detecting a shift in median or mean of hydrometeorological data. Stochastic Environmental Research and Risk Assessment (SERRA), 16, 307-323. doi:10.1007/ s00477-002-0101-9

Yue, S. and Wang, C.Y., 2002b. Applicability of prewhitening to eliminate the influence of serial correlation on the Mann-Kendall test. Water Resources Research, 38 (6), 41-47. doi:10.1029/2001WR000861 